INT’L. J. SELF-HELP \& SELF-CARE, Vol. 6(1) 9-41, 2012

\title{
REFRAMING DEMENTIA IN SWEDISH SELF-HELP GROUP CONVERSATIONS: CONSTRUCTING CITIZENSHIP
}

\author{
LINDA ÖRULV \\ Center for Dementia Research (CEDER) \\ Department of Medical and Health Sciences \\ Division of Health and Society \\ Linköping University, Sweden
}

\begin{abstract}
This study explores on a micro-level the activity of a self-help group for persons with dementia in Swedish municipal care, based on audio-recordings from 18 months' ethnographic fieldwork. The study focuses on the discursive construction of a shared meaning perspective and its inherent possibilities for liberation. Applying a citizenship perspective, the study approaches people with dementia as vulnerable to marginalization while at the same time capable of agency within the boundaries of their condition. The findings paint a complex picture involving opportunities and limitations of experiential knowledge, issues of double stigmatization, and constructs of being interrelated with other people and with the surrounding society. In the center is the overarching struggle of retaining citizenship in the face of the evolving disease.
\end{abstract}

Key Words: dementia, citizenship, self-help groups, mutual support, meaning perspective, experiential knowledge, discourse, Sweden

(c) 2012, Baywood Publishing Co., Inc. doi: http://dx.doi.org/10.2190/SH.6.1.c http://baywood.com 


\section{INTRODUCTION}

In Sweden, as in other modern Western societies, Alzheimer and other progressive dementia diseases bring to the fore deeply rooted existential fears. Involving cognitive impairment, loss of autobiographical memories, and ultimately disorientation and behavioral changes, the diseases challenge core cultural values of self-control, awareness, and personal responsibility (Ballenger, 2006). In spite of many recent efforts in dementia care and research to "reinforce the person" rather than focusing merely on the disease and its symptoms, dementia is still commonly associated with stigma or shame (Corner \& Bond, 2004; Vernooij-Dassen, Moniz-Cook, Woods, De Lepeleire, Leuschner, Zanetti, et al., 2005). Dementia may simply make people "acutely uncomfortable" (Sterin, 2002, p. 8). In many contexts it is an unspeakable topic, one that makes people shy away as they do not know how to deal with the subject. This makes it difficult for the diagnosed individuals to share their experiences with others to help make sense of and actively cope with their situation.

On the whole, people with dementia often lack a venue for sharing and support and for reflecting on their situation. This is in spite of the fact that today many people with dementia diseases spend a considerable part of the time after receiving a diagnosis living independently in the community — in the early stages with a minimum of supporting measures. Thus it is reasonable to assume that they could benefit from mutual support. In this explorative case study I wish to shed some light on the qualitative benefits that might evolve from the kind of mutual help that takes place in a small local Swedish dementia self-help group, and also on the difficulties that may be involved. As a communication researcher I am especially interested in the shared meaning-making that takes shape in the discourse. Is it possible for people with dementia, with the cognitive difficulties that their condition entails, to evolve the same kind of liberating perspective on their situation that is often found in other self-help groups (Borkman, 1999)? This question is interesting also from a citizenship perspective in terms of political agency. A citizenship perspective approaches people with dementia as vulnerable to marginalization while at the same time capable of agency within the boundaries of their condition (Bartlett \& O'Connor, 2007). Could self-help groups allow people with dementia to develop a voice of their own?

In the Swedish context, efforts are made to educate and provide support groups or other psychosocial support programs for the next of kin. In national guidelines for dementia care, this is established as a major priority (priority level 2 out of 10; National Swedish Board of Health and Welfare, 2010). However, corresponding efforts involving the persons actually diagnosed are not mentioned. The lack of available support and patient education for people with early-stage dementia has been criticized before (Goldsilver \& Gruneir, 2001; Mountain, 2006; Pearce, Clare, \& Pistrang, 2002). The criticism is still valid in relation to Swedish conditions, with a few innovative exceptions. To my knowledge there 
have been three such endeavors within the public sector in the course of the last decade, two of which were developed in collaboration with persons diagnosed with dementia diseases. They were all local initiatives driven by a few enthusiasts. The Swedish State Inheritance Fund, taking an interest in innovative projects only, has also recently funded two similar activities within the voluntary sector (Taghizadeh Larsson, Jeppsson Grassman, \& Whitaker, 2010). On asking around, I was often met with surprise and the attitude that people with these kinds of difficulties would most likely not benefit from mutual support.

Just as has been described with regard to the US (Beard, Knauss, \& Moyer, 2009), family members have historically been positioned as the real victims of dementia diseases since those diagnosed have been assumed incapable of insight. Those diagnosed have in general been excluded from the public discourse concerning their own disease (cf. Beard \& Fox, 2008). Only recently have health social movements related to dementia started to include patients as spokespersons (Taghizadeh Larsson et al., 2010; cf. Beard, 2004, for the US context). Even today Swedish internet websites often describe dementia as "the disease of the next of kin." As Beard et al. (2009, p. 227) put it, "[s]uch views position persons with dementia as 'objects' of their illness rather than 'participants' in it."

\section{Toward a Reframing of Dementia (Again): A Citizenship Perspective}

Since the late 1980s it has been argued that we need to rethink the way we frame dementia, to include not only technical but also personal aspects (e.g., Kitwood, 1988) - applying a so-called personhood perspective. Giving recognition to the impact of factors in the interactional environment, rather than merely neurological processes, the personhood perspective entails a less pessimistic view of the course of the disease. Relationships supporting and enabling the person may put the decline on hold for a while and even afford some improvements. Promotion of personhood in care practice includes psychosocial interventions, environmental changes, and assistive technologies. The personhood perspective has thus significantly changed the way we treat people with dementia. In research, the personhood approach has also entailed an increasing interest in the perspective and voices of persons with dementia (see Bartlett \& O'Connor, 2007 , for an overview).

Nevertheless, in public discourse dementia diseases are still commonly ascribed meaning in line with a pessimistic deterministic reasoning that is partly unwarranted (Mountain, 2006). People with dementia have to face not only the symptoms of the disease - which is, without a doubt, hard enough - but also the negative expectations from people around them (Beard \& Fox, 2008; Sabat, Napolitano \& Fath, 2004). This may render passive behavior, social stigmatization and isolation and possibly keep people from seeking care in the first place (Corner \& Bond, 2004). In terms of socio-politics, it keeps people with dementia 
"on the periphery of any benefits that can be derived from [...] policies that support people with long-term conditions" (Mountain, 2006, p. 442).

Beard et al. (2009) argue that even today there is indeed a need for a reframing of dementia "to challenge the normative victim-orientation and the social disadvantages of such biomedical reductionism" (p. 227). Their work is one of several recent studies with a departure in the perspective of individuals and groups of people with dementia who have somehow taken a stand against the common image of passive dementia "sufferers" and against the social barriers that they face in their everyday life. Based on internet surveys, among others with members of two dementia advocacy organizations and a support group, Beard and co-workers found that persons with early-stage dementia are able (under the right circumstances) to use a large variety of coping strategies to actively manage the challenges of everyday life (cf. Clare, 2002; Pearce et al., 2002). Moreover, a majority of the respondents reported that advocacy enriched their lives and allowed them to meaningfully engage in society. As the authors describe it (Beard et al., 2009), the persons demonstrated agency by creatively adapting and constructing "meaning, order, and selves that were valued" in order to "achieve an identity without the stigma surrounding rhetoric of irreversible devastation and threats of complete self-annihilation" (p. 234).

Similar findings have been reported by Clare, Rowlands, and Quin (2008) in their 2-year qualitative internet-based study on the experience of belonging to the self-help network DASNI, Dementia Advocacy and Support Network International. The challenges of dementia included feelings of loss, struggle and uncertainty on many levels, but the participants found a sense of collective strength in engaging in the network. Gradually, according to the study, they came to reject the passive patient role. Together they increased their knowledge, found words to express their experiences and could (at least to some extent) counteract the challenges both of the disease and social attitudes. Participating in DASNI made them feel that there could be a life after diagnosis - by way of mutual support and collaborative advocacy they could make a valuable contribution and even make a change, something to take pride in. This helped them to confront their own difficulties and fears and made the ongoing process of adjustments a little easier.

There is perhaps a little more "readiness" nowadays among policy makers and service providers to listen to the perspective and voices of people with dementia (Clare et al., 2008). Attitudes are slowly changing in favor of new models of service delivery that will, hopefully, promote self-management (Mountain, 2006). In this context, mutual support and collaborative advocacy offer potential for social change and influence on both policy and practice. Several researchers predict that earlier diagnoses and increasingly effective medication will make it possible for people with dementia diseases to be actively involved in advocacy efforts and to have their voices heard like never before (Beard \& Fox, 2008; Clare et al., 2008; Mountain, 2006). 
In line with this, Bartlett and O'Connor (2007) suggest that the time has come to broaden the lens for dementia practice and research to approach those diagnosed not only as persons worthy of our respect, but also as citizens. Such a perspective, they argue, recognizes the impact of power relations and social structures and allows for a contextualization of personal experiences within a broader socio-political context. It also recognizes people with dementia as individuals relating to society "through the power dynamics of everyday talk and practice" (Bartlett \& O'Connor, 2007, p. 112). The practice of citizenship may take many different shapes. Being involved in advocacy efforts as described above is one, but political agency may also be expressed "out of the public eye" (Bartlett \& O'Connor, 2007, p. 112) in acts of resistance or resilience-including everyday actions that may seem banal, yet have both personal and political meaning. The concept of citizenship, as applied by Bartlett and O'Connor (2007), thus deals with the complex interplay between micro and macro levels, between agency and structure. People with dementia are seen "simultaneously as both actors in constructing their own reality, and constructed by prevailing discourses" (Bartlett \& O'Connor, 2007, p. 114).

\section{Reframing in Self-Help Groups: Developing a Liberating Meaning Perspective}

Self-help groups provide a space in which people can learn, about the problem they share, from their own and their fellows' experiences - voluntarily and in a spirit of mutual support (Borkman, 1976, 1999). In the case of dementia this would imply a space that allows the participants to address and openly discuss dementia-related fears and concerns from their own perspective and in their own language. Self-help groups encompass the two concepts of self-help and mutual aid, often summarized as "You alone can do it but you cannot do it alone." This means that participants are willing to take responsibility for their behavior and well-being, with the moral support of their peers in a mutual aid context (Borkman, 1999).

According to Borkman (1976, 2008), the most distinctive feature of self-help groups is experiential knowledge. This means that the group members all have personal stakes in how to interpret the common problems they encounter in their everyday lives, and together they can explore new meanings and new approaches to them (Borkman, 1999). They may use professional knowledge, but translate it into a form that fits it into their lives on a practical everyday level. The groups commonly deal not only with medical issues but also with other aspects of lived experience. This includes matters of everyday life - physical, emotional, mental, practical, relational, and highly personal matters - and contacts with health and social care systems. Sharing stories and reflections on all these matters, the groups over time develop a body of shared understanding, a collective 
experiential knowledge that becomes "a source of authority on what it is like to live with, through, and beyond the condition" (Borkman, 2008, p. 216).

This knowledge, Borkman (2008) argues, is potentially the source of new selves, social identities and communities; it is the source of new meaning perspectives that challenge prevailing public views of a condition and of what people with the condition are like. As meaning perspectives are the results of complex social processes, the knowledge, values, and explanation models expressed may vary significantly between groups. Meaning perspectives come in many different shapes. They do seem to have one thing in common, though, and especially when some kind of stigma is involved. Borkman (1999) maintains that people with conditions associated with stigma need a liberating meaning perspective, one that helps them to "redefine their humanity" (p. 115). Such a perspective on dementia would evolve meanings, identity and agency apart from devaluing conceptions of dementia that the group members face in their everyday life - similarly to what has been found in self-help groups for other potentially stigmatizing conditions (Adamsen, 2002; Borkman, 1999).

For this to happen, the group members must be devoted to learning and developing together and prepared to actively face the difficulties posed by their mutual problem. Also, the groups need not be controlled by any professional authority, but free to develop their own meaning, purpose, and internal relationships through the members' mutual efforts. When using professional facilitators, groups often (but not always) become more structured and hierarchical and more dependent on professional authority (Borkman, 1999). Over the years many researchers have argued that group processes are altered when self-governance is replaced by external control, for instance in terms of decreased commitment, more passive behavior and less empathy and self-disclosure (Jacobs \& Goodman, 1989), or less cohesion, expressiveness, and self-discovery (Toro, Reischl, Zimmerman, Rappaport, Seidman, Luke, et al., 1988). Others, however, point to what can be learned from cooperation, as long as professional involvement respects core values of solidarity and equality (Adamsen, 2002).

Borkman (1999) describes three stages of development with regard to the group's meaning perspective. In the first stage, the "fledgling" group struggles to develop its meaning perspective-how to define the shared problem and how to resolve it, what identity to assume and how to work as a group. A more developed group, secondly, has a meaning perspective that works for its members. The members thus have faith in their experiential authority and are able to apply their acquired knowledge to make their lives easier. In the third stage, finally, the group is certain of its experiential authority (for good and for bad, in varying proportions).

I believe a citizenship perspective could provide a useful theoretical framework for exploring what takes place in dementia self-help group conversations. Adamsen (2002) argues that "self-help groups promote interaction between the individual and the surrounding society" insofar as it "provides a shift from a victim 
position to an actor position" (p. 227). After all, what Borkman (1999) refers to as the development of a liberating meaning perspective in self-help groups, is not only a personal matter. Nor can it be reduced solely to matters of group interaction, although the dynamics of interaction are crucial. It is also a matter of relating to the wider social and cultural context, claiming a say in what stories are to be told. In that respect, the personal, the interpersonal, and the political/ structural are interrelated (Baldwin, 2008). The local group is after all not a closed setting, not a "self-contained social system"; its participants orient to values, beliefs, interests, and practices of the society and culture they are all part of (Milofski, 2008, p. 70) - and in their collective stories they may negotiate them.

\section{Self-Help Groups and Dementia}

Except for the case of internet-based networks, groups for people with dementia described in the available literature are generally professionally led support groups. Several researchers have reported positive experiences from these groups. Many describe the groups in terms of camaraderie/companionship, affirmation and cohesion (Goldsilver \& Gruneir, 2001; LaBarge \& Trtanj, 1995; Mason, Clare, \& Pistrang, 2005; Yale, 1999; Yale \& Snyder, 2002). Meeting others with the same diagnosis and feeling that one is not alone seems to be crucial (LaBarge \& Trtanj, 1995; Mason et al., 2005; Yale \& Snyder, 2002). Some also

found indications that the group activity resulted in personal development and interpersonal learning (Yale \& Snyder, 2002), increased abilities to express feelings and enhanced understanding of one's behavior (Yale, 1999), or improved confidence (Goldsilver \& Gruneir, 2001). Participants shared information, coping strategies, emotions, and confidences and were able to deal with negative feelings and openly discuss their difficulties (LaBarge \& Trtanj, 1995; Mason et al., 2005; Yale \& Snyder, 2002). The groups were forums for mutual support, compassion, and altruism, and for catharsis (LaBarge \& Trtanj, 1995; Yale \& Snyder, 2002).

What seems to be missing from most of the literature is the development of shared meaning perspectives. Perhaps this has not been a matter of priority in dementia research, or perhaps the tight reins of professional authority in the professionally led groups have left little scope for such perspectives to be developed?

Most of these studies do emphasize the role of professionals, because of the special difficulties that come along with dementia. For instance, Goldsilver and Gruneir (2001) suggest that facilitators be prepared to accommodate to fluctuations in the affect, behavior, communication, and cognitive functioning. Also they should gently support the group members and redirect them back on track when called for. Facilitators, the authors argue, must be "ready for the unexpected" (p. 113). In a similar vein, Yale and Snyder (2002) advise on how to handle participants' repetitions, communication difficulties, and agitation and on how to help individuals and their families deal with their losses. They describe 
the professional role as maintaining a delicate balance - integrating feelings of loss, fear, and frustration with the opportunities, capabilities, and joy that may be embraced in the present. The facilitator, they maintain, must monitor this process. Furthermore, facilitators are ascribed great responsibility in determining when a participant is "no longer able to participate effectively in the support group and needs to move into other programs in the community" (p. 240), as well as in handling the ex-participant's feelings of abandonment and rejection, and anxiety and grief on the part of the remaining participants.

Mason et al. (2005) provide a nuanced discussion of the professional role, based on a combination of video recordings and interviews with the participants of two different support groups. The interviews indicated that the facilitators' work was much appreciated and central to the functioning of the groups insofar as they kept the conversation going and were able to help when participants had memory and communication difficulties. The facilitators functioned as "anchors" in the conversations, providing stability and coherence. At the same time it was clear that the participants saw the professionals as leaders and teachers rather than facilitators. Apparently the professionals were in control of the topics as well as the destiny of the group. Although the groups were described by their facilitators as being both discussion-based and member-led, the observations showed that nearly three quarters of the interactions in the groups involved a facilitator. Most of these interactions occurred between a facilitator and a single member, leaving little scope for mutual aid.

The group interaction was thus quite dependent on the facilitator. Mason et al. (2005) acknowledge that dementia-related difficulties may in most cases call for some kind of professional facilitation. Most likely this will be necessary at least in the long run (cf. Taghizadeh Larsson, Grassman, \& Whitaker, 2010). On the other hand, Mason et al. (2005) raise the important question of whether, with less professional control, group members with early-stage dementia could somehow be encouraged to take on a more active role. This issue requires further empirical investigation.

One interesting contribution was made by Beard and Fox (2008), who studied Alzheimer support groups sponsored by diagnostic centers or the Alzheimer's Association. Relying on biomedical practices and theories, these groups tended to apply more of a clinical gaze also with regard to social and personal matters. Nevertheless, the group members found ways to avoid becoming mere recipients of the diagnosis. They actively used their diagnosis as a resource not only to understand what they were going through, but also to legitimize forgetfulness, manage and negotiate the terms for social interaction, and to gain support when needed. Thus, they pragmatically incorporated their diagnosis into their selfidentity, while at the same time fighting to evade the status of a victim. In group conversations, the participants reportedly developed an active approach in relation to their disease and to their own self-identity. Similar to participants in advocacy networks mentioned earlier (Beard et al., 2009; Clare et al., 2008), they 
also found strength in the collective identity of the group and in being able to make a contribution. Despite the dependence on professional knowledge in this case, I would say that these findings point to the possibility for dementia groups to actively develop meaning perspectives of their own.

What kind of meaning perspective is developed is quite another issue. The special challenges of dementia diseases might have a negative effect on this development, due to the fact that the diseases are progressive. Not only are the members' cognitive and communicative resources for dealing with their challenges increasingly affected over time, the members will also continuously have to face new and gradually tougher challenges. The question is whether it is at all possible under these conditions to ever reach a liberating meaning perspective that "works" for the group members and helps them to resolve their problems. On the other hand, Karp (1992) argues that experiencing chronic illnesses of uncertain outcome may entail an even greater need to construct some kind of interpretive framework. How this is handled by the self-help group is an empirical question.

\section{METHODS}

This is an explorative case study of social interaction in a dementia self-help group within the context of community care in a small Swedish municipality (around 16,000 inhabitants). The case is a small-scale local initiative starting out from the diagnosed individuals' own ideas, wishes, and needs. In this study I explore on a micro-level the self-help group activity as a discursive space, focusing on how the participants go about creating their own framework in group conversations. I am interested in to what extent the context of the self-help group may promote the development of a liberating meaning perspective in this group of individuals with cognitive impairment. More precisely, my research questions are as follows: How do the group members discursively construct a shared perspective of living with dementia in the conversations? Is it relevant to understand these constructs in terms of a liberating meaning perspective? If so, how is the meaning perspective affected by the special challenges that dementia poses? Finally, I discuss what the empirical findings mean from a citizenship perspective.

\section{Collection of Data}

For a long time I had wanted to study self-help groups for people with dementia when I finally came across some information on Ingrid's group (pseudonym) on the internet. I made contacts with the professional coordinator, who brought up the matter for discussion with the group in their following meeting. The group wished some further clarifications about my intentions before deciding. They also asked me to make myself acquainted with an educational film they had made, 
in which the participants, some of their coping strategies and the group activities were introduced. After making clear that I was interested in people with dementia as agents using their own resources in interaction, I was then invited to present myself at one of their meetings. The group members unanimously decided to welcome me to the group. I was told that they wished for their experiences to become more widespread.

I then followed the group activity for one and a half years (so far), audiorecording 22 meetings of two hours each. I chose not to use a video camera because, the way the group was seated, useful video data would require moving the camera back and forth in order to capture facial expressions and gestures. That would have been too intrusive. Instead I gave priority to sound quality and took complementary notes to capture some of the non-verbal expressions and contextual information. Interviews were made with the initial coordinator and with two group members who had key roles in the development of Ingrid's group.

\section{Approaching the Data}

Recordings and field-notes from actual group meetings provide the opportunity to study collective sense-making in its making. They provide access to group members' own language, concepts and concerns, with minimal interference from me as a researcher (cf. Linell, Wibeck, Adelswärd, \& Bakshi, 2001). The recordings were indexed with regard to both content and discursive patterns. In defining what was noteworthy I worked close to the empirical data, following the participants' lines of argument and topical pathways rather than using pregiven categories. In relation to the research questions, three analytical themes emerged which will be dealt with in separate sections.

In the analysis, I strived to do justice to what, from the perspective of the participants, it was all about, using an actor-oriented approach. Sequences were selected for deeper analysis so as to capture both patterns and contrasts in the data. The close analysis of certain sequences of social interaction was related to a wider context of recorded data and field-notes. This way of analyzing emphasizes the importance of the interaction between the participants as well as the context. That is, the immediate context, but also a wider context of related situations and background information. In providing detailed accounts of the discourse and contextualized information, I hope that the reader will be able to appraise whether or not my interpretations are reasonable. The purpose of this research is not to generalize, but to explore "realms previously not understood" by way of in-depth portrayal (Beard, 2004, p. 425).

\section{Representing and Translating Recorded Data}

The selected sequences were transcribed in detail, including paralinguistic aspects such as length of pauses, rhythm of speech, and voice quality. The analyses were based on the Swedish transcripts and, as a precaution, on the original audio 
data. Translations of transcripts are always problematic. This is the way I have chosen to handle the issue.

Although a translation as close to the original as possible has been the aim, idiomatic expressions have been replaced with similar English idioms in order to preserve the flow of the language. Correspondingly, language errors have been translated into similar errors in the English language when applicable. Emphatic stress has been marked and translated so as to maintain the meaning of the original emphasis, rather than, for instance, the placing of the word in a sentence when the word order differs between the languages. In the cases of overlapping speech (two or more participants talking simultaneously), the word order in the translation did not differ to an extent that compromised the representation of the overlap. The overall principle for translation was the aim to present accurately the original meaning and nuances of utterances and also to do justice both to participants' linguistic competence and the dramatic qualities of their speech. The Swedish originals are available from the author on request.

In the final text transcripts of excerpts have been simplified, using the following key:

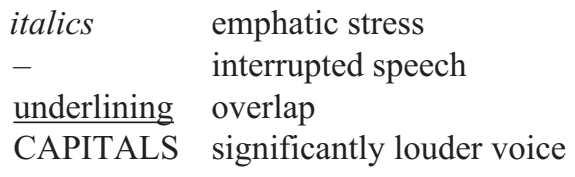

\section{The Case "Ingrid's Group": Presentation and Background}

The case I am studying does not belong to any larger self-help organization but is a local initiative. The activity is based within municipal care (public sector), with its administrative tasks performed by a professional coordinator ("Marie") and to some extent by an assisting colleague ("Mona"), both of whom are also present at the meetings. Thus, the group is to some extent dependent on other resources. Some kind of professional involvement is in fact quite common in Scandinavian self-help groups (Adamsen, 2002). However, the locus of power is within the group (Schubert \& Borkman, 1991). The framework is highly dependent on the diagnosed participants themselves (Borkman, 1999: "experientialists"); there is no professional agenda and no hierarchical structure, and the participants' own initiatives and wishes are highly decisive for what takes place within the activity and what topics are brought up in conversation. The group is a miniature democracy (Jacobs \& Goodman, 1989) insofar as neither the professionals nor any other persons have the authority to direct other members of the group. Participants are free to make sense of their condition and situation in their own way, developing their own meaning perspective, and mobilize their own resources. This distinguishes the group from a professionally run support group (Borkman, 1999). 
The group consists of (at most) seven persons (mostly women, + two professionals and one researcher present) getting together every other week to talk about their lives with dementia, to learn coping strategies and to support each other. Their ages span from 63 to 83 . They are all able and willing to talk about and reflect on the impact of their disease on their everyday lives; this is a prerequisite for taking part in the group activity. The following experientialist participants appear in the recordings:

$\begin{array}{ll}\text { Sinikka } & \begin{array}{l}\text { female, Alzheimer's disease (early-stage) } \\ \text { Inga }\end{array} \\ \text { Karin } & \begin{array}{l}\text { female, vascular dementia (early-stage) } \\ \text { femalzheimer's disease (early-stage) } \\ \text { Ingrid }\end{array} \\ & \begin{array}{l}\text { which is not clear) } \\ \text { female, mild cognitive disability due to vascular injuries }\end{array} \\ \text { Ulla } & \text { male, Alzheimer's disease (getting worse) } \\ \text { Karl } & \text { male, vascular dementia (displaying some difficulties in main- } \\ \text { Stieg } & \text { taining focus in multi-party conversations) }\end{array}$

Note: In the analysis I do not differentiate between diagnoses as the participants themselves generally do not. Ulla and Ingrid have both been re-diagnosed with mild cognitive impairment subsequent to earlier dementia diagnoses, as they did (at the time) not meet the criteria for dementia. Still, the participants almost exclusively orient to dementia as their common problem, irrespective of what differential diagnoses they have been assigned.

The number of participants has changed over time, from seven participants when the data collection started to five today. Karl moved into residential care in the beginning of the study due to the course of the disease. The youngest group member, Ulla, who had only a mild cognitive disability, moved to another location to start over; she felt she was no longer accepted in the community (outside Ingrid's group).

Initially the group activity started out as a dementia education planned and arranged by two women with dementia diagnoses and a professional dementia coordinator who all cooperated. This was part of a larger national project which aimed at involving persons with dementia in their care planning. One of the experientialists contributing, Ingrid, had already gathered some of her neighbors for informal meetings on forgetfulness on her own initiative, and also contributed to this national project in several instances as an advisor, as a lecturer, and as a mentor. Now she was eager to take part in this venture of planning an education addressing people with dementia. Ingrid and the other woman (who is no longer part of the group) played a major part as "experts" on living with a dementia disease, and initiated the group discussions. The professional coordinator, who was a former nurse, contributed with her professional knowledge in accordance with the participants' wishes. Based on what had emerged as central issues in the discussion, themes for the following sessions were democratically decided. 
After these initial sessions, some participants agreed to both contribute to and take part in another round of sessions intended for new participants. This second group wished to continue meeting regularly after the education had ended, and they needed help with administration and location. After some considerations, it was clear that this could be arranged within the municipal dementia care. This came about, with two additional participants and with a different coordinator, Marie - the initial coordinator's student protégée who was now a qualified nurse and the new official local dementia coordinator. "Ingrid's group" was born. When I came into the picture as an observer, Ingrid's group had already been meeting regularly for two years. Some participants had left the group due to the progress of their disease, and one more person had joined it (invited by another participant). By that time Marie had also involved her colleague Mona, responsible for a community-based meeting place for the elderly and the disabled, in the group meetings.

The participants not only support each other, but have also to a varying extent given voice to their thoughts and experiences in the media (mostly locally) and lectures (within university education and professional training and in public performances), although this is getting increasingly difficult due to the progression of the disease. This was part of the group activity right from the start. Ingrid's group, thus, involves sharing and support and advocacy efforts, the latter aiming at improving policies and treatment as well as the public framing of dementia. These advocacy efforts, however limited the opportunities they may have to impact health policy and practice, are of course central to the group's claims of citizenship and intimately connected with its meaning perspective. They will, however, be subject to further study elsewhere. For the purpose of this article, I will focus on the group conversations.

\section{The Group Conversations}

The group conversations within Ingrid's group are very informal. The professionals Marie and Mona are first on the spot, preparing coffee and sandwiches. Then the experientialist participants drop in. They all hug and ask about each other's health and, if applicable, share information about those who are unable to attend. When they are all seated they repeat the greetings and exchange of information more officially for everyone to hear, or simply continue talking. Sometimes Marie and Mona, the professionals, may share some practical information. Then the conversation follows its own course. Somewhere in the middle of the session Mona serves some coffee and sandwiches. The conversation goes on until time is up and somebody has to rush along to another activity or until somebody's ride home arrives.

Themes addressed in the conversations are dementia-related difficulties as experienced in everyday life; other health issues; the diagnosing process and the lack of follow-up procedures; treatment, both in health care and in daily life; 
relations to one's next of kin; future concerns and fears and issues of control; social criticism; how to reach out with information and make an impact; concerns about each other and about mutual friends; and social talk. Sometimes a single participant may hold the floor for a longer period of time, telling a story or warming up to her subject. However, it is common that sequences involve several participants taking turns, overlapping each other's speech, interrupting and finishing each other's sentences. The conversations are marked by notable candor. Within this context different opinions are allowed, and it is safe to express strong feelings and bring up sensitive topics (cf. Jacobs \& Goodman, 1989). Just as has been described in cases of HIV and cancer (Adamsen, 2002), the group is a "free space" where participants are not expected to put on a happy face. Humor and jocularity do however play an important part in dealing with difficult issues - hearty laughs, dark or very subtle humor-accompanied with profound consideration for and sensitivity to each other's feelings (cf. LaBarge \& Trtanj, 1995; Yale, 1999).

Marie and Mona may sometimes take on their professional roles to make clear some facts, for instance about the way home help service or residential care operates. They may occasionally share stories from their work in elderly care. However, they may also share private experiences, applying more of a friendly framework. They often stress how much they have learned from the participants and how important this knowledge is, both to them in their work and to the world. When the participants are critical of the health care system, Marie and Mona are often their most devoted supporters. Thus, experiential knowledge is the major source of authority (cf. Borkman, 1976, 1999, 2008; Schubert \& Borkman, 1991). In talking to me about her role within the group, Marie stresses the importance of letting the group run itself and having faith in this process. It is, however, obvious that both Marie and Mona see themselves not only as resources but also as members of the group, as well as friends, and they are also treated that way by the experientialist participants. There is no distance between the professionals and the rest of the group, except for the fact that their personal experiences of dementia differ.

\section{Ethical Considerations}

Information about the study was provided both in writing and in face-to-face conversation. The information included purpose and procedure and the fact that participation was voluntary and confidential. All participants consented in writing, except for Karl who preferred to confirm his consent on tape. I asked Marie, the coordinator, to act as an intermediary in case anyone wished to anonymously express their concerns about the study or request for its termination, to ensure that nobody felt undue pressure to take part in the study. I also asked her to be attentive to any sign of uneasiness because of the ongoing study. During the research process, the participants were reminded of the possibility to omit 
sensitive data from the study. One of my greatest concerns was that my presence and the recorder would potentially be intrusive to the group activity and make the group members feel uncomfortable. However, my experience was rather as has been described by Carlsen (2003, p. 294):

At group meetings I was warmly welcomed by the participants who seemed to view my presence as a sign of my commitment to their cause. During group discussion the participants seemed too engaged in the discussion to mind my presence.

Pseudonyms are used throughout the study to protect the integrity of the participants.

\section{FINDINGS}

The findings are grouped into three main headings that represent three analytical themes: Claiming mutual experiential knowledge; In-between trivialization and dismissal — facing double stigmatization; and Being part of a bigger picture. These themes were empirically generated, based on topical pathways and lines of argument within the recorded conversations. The first theme deals with how mutual experiential knowledge is put forward as a major source of authority in the group conversations, and how it is discursively constructed. It also deals with the special challenges that deteriorating cognitive functioning poses on this process. The second theme is about the complex challenges of stigmatization and how they are met when establishing a shared perspective of living with dementia. The third theme, finally, addresses matters of being interrelated with others, on various levels, and with society — as agents, depending on other agents, and as citizens.

\section{Analytical Theme 1: Claiming Mutual Experiential Knowledge}

This thing, you know, referring uh to dementia as the disease of the next of kin, it drove me damned furious in the beginning [- - - ] when they took away my identity. Suddenly my husband was the one who was ill. But I was the one who (pause) had the consequences. So (micropause, i.e. minimal pause) I think that's something terrible actually. (pause) I was so angry you see. And wherever you looked they were talking about (micropause) and I looked on the web a lot, among other things, for this. And all the time they were going on and on about the disease of the next of kin.

Whose disease is it anyway? In the excerpt above, 66-year-old Sinikka, diagnosed with probable Alzheimer's disease 4 years earlier, expresses vividly her urgent wish to retain the preferential right of interpretation in reference to her own disease. After all, she is the one experiencing its consequences first-hand. She is what Borkman (1999) refers to as an experientialist. Her standpoint is 
significant to the members of Ingrid's group. In line with Borkman's ideas (1976, $1999,2008)$, the group conversations commonly revolve round participants' experiences and their accumulated body of experiential knowledge. In this particular example the contributions of other participants in the conversations (Yeah, exactly; Uh-huh, etc.) have been omitted.

\section{Establishing a Common Understanding}

In their many conversations, the members of Ingrid's group continuously compare their experiences as their dementia diseases evolve. In some respects their individual experiences differ. Personal accounts and stories then contribute to a more nuanced knowledge of the matter, acknowledging variations in the progress of the disease and the fact that they are all different persons.

Inga: Something I've noticed that I've reacted to a lot recently is answering the phone. People may speak to me for a long time on the phone and I haven't understood a thing.

Karin: No! (laughing)

Ingrid: No.

Karin: How annoying!

Ingrid: I guess I'm a bit familiar with that.

Inga: No. Yeah, that's so awful.

Karin: Yeah, I can see that.

Inga: And then you'll have to say "Yeah, but what do you mean, what are you talking about?'

Karin: Yeah. You can't really think.

Inga: Your brain's slow on the uptake. (difficult to translate; the original meaning rather indicates that there is no uptake at all)

Karin: Uh-huh, no. No, that-

Inga: It's it's like it's been switched off and it takes a while while

Karin: Uh-huh.

Inga: for it (micropause) to start reacting.

Karin: Yeah, I see what you mean but but I'm thinking it (inaudible) must I don't react like that. I can handle that now, oddly enough. But it's so a- aWe are all so indi- individual all of us. We react differently to different things, you know.

In the excerpt above, Ingrid and Karin compare themselves to Inga's description of her difficulties in answering the telephone. They can both relate to her 
experience, although Karin notes that she herself does not (yet) react the same way in this particular situation. In spite of her differing experiences, Karin joins Inga in her account. She contributes with evaluative statements ("How annoying!," "Yeah, I can see that"), showing her engagement in the matter. She then adds an aspect ("You can't really think") upon which Inga elaborates further. In this way Inga's account is co-constructed as something more than just a personal problem. In the interaction it is established as relevant to the group's shared perspective of living with dementia. In the end of the excerpt, Karin frames the account as a variation of their common experience.

More often the group members accentuate what they have in common. Similarities are brought forward in the conversation as a way of both establishing a shared understanding and implying a shared interpretation of what it is all about (Ohlsson, 2009). In these co-produced accounts, personal experiences are made general and collectivized (Bülow, 2004), contributing to a collective identity (Ohlsson, 2009). Through this reciprocal process, mutuality develops (Avis, Elkan, Patel, Walker, Ankti, \& Bell, 2008; Borkman, 1999). This is, for instance, the case when Karin, Ingrid, and Sinikka discuss their recent failures in the kitchen, starting with frying pancakes.

Karin: It's impossible. And I blame my new stove for that. (widespread laughter)

But I'm sure.

Ingrid: Last time I blamed my pancake spatula. (widespread laughter)

Karin: You did? (laughing)

Ingrid: Yeah. That must've been it. (ending utterance with laughter in her voice)

Karin: The same uh (pause) griddle and spatula and everything and the same regular batter, but what the devil, those pancakes don't seem to get any color. (laughing)

(Inga and Marie laugh)

So that was the last time I did that.

Ingrid: That's the worst thing, you know, is that you stop trying when you've failed

Karin: Yeah.

Ingrid: a couple of times, you know.

Karin: Yeah. I've made hundreds of pancakes and it's like this, I can't-

Sinikka: Now I've made the decision, just now, to stop cooking.

Karin: Oh, I see! (laughing)

Ingrid: Yeah? 
Karin: Yeah, but you've-

Sinikka: 'Cause now I've burned two uh two pans.

Ingrid: No, not another pan?

Karin: ANOTHER PAN? (laughing)

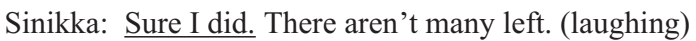

The three ladies discursively mirror each other's difficulties. In the beginning of the excerpt, Ingrid also mirrors Karin's jocular way of blaming the equipment for her own failure, to the other group members' amusement. They all join in what I interpret as laughter of recognition. Ingrid's use of the non-specific Swedish pronoun "man," translated as "you," gives her statement a more general validity; "man" typically refers to any person in that kind of situation. This is further reinforced by her use of the Swedish adverb "ju" twice in the same sentence, translated as "you know," which implies that they all share the same conclusion (Ohlsson, 2009). The general statement that one stops trying after a couple of failures seems to be what cues Sinikka to add her contribution, as she has actually decided to stop cooking for that very reason. In her case the failure is, however, somewhat more drastic. Both Ingrid and Karin emphatically demonstrate their knowledge of Sinikka's previous incident of what was then described as almost burning down the house.

In fact, due to Sinikka's stories of her misadventures, "burning down the house" has become a prototypical example to which the group members often come back in their discussions. It is often used as a metonymy for their collective fear of losing control and used as a resource in arguing for their need to be able to take action (cf. Linell et al., 2001) — to move into some kind of more sheltered living or, as that opportunity is not yet available, to have safety devices installed at the public expense as is customary in cases of disability.

The group members share their various coping strategies, contributing to the group's accumulated knowledge. For instance, Sinikka has taught her dog to search for his mistress. Ingrid's strategies for baking with poor memory are well known to the rest of the group: for each cup of flour she pours into the batter, she moves a spoon or fork from one place to another. These kinds of strategies are part of the group members' common frame of reference, referred to as common knowledge and sometimes in a joking manner. In many instances the group members express their confidence in their own experiential knowledge. This is sometimes phrased in terms of how they have been able to help others and how appreciated their lectures and media performances have been, or how much professionals and others could learn from them in certain matters. However, there are also many instances of faltering confidence due to disease progress. 


\section{In Battle with Time}

Karin regularly gets together with some friends who live in the same building, although she finds it increasingly difficult to get on with it. The thought of engaging socially makes her really anxious. She would rather just crawl into bed instead of meeting with her friends, although she knows that she will enjoy herself once she gets there. Luckily, her friends are very persistent and, as she describes it, won't take no for an answer. On these occasions her friends have a hard time believing that Karin has Alzheimer's disease. In the self-help group conversations, Karin often remarks on this. She herself has to live with the Alzheimer experience all the time, not just those merry moments when she is on top. When talking about this, Karin, Ulla and Ingrid reflect upon the topic of self-awareness.

Ulla: That's not a strange thing for people to say, you know (that they have a hard time believing that Karin has Alzheimer's).

Karin: No.

Ulla: About you.

Karin: No. Well, no no. (laughing)

Ulla: When you're talking an' (micropause) I mean-

Karin: Yeah.

Ulla: Like (micropause) very much aware of (micropause) your pieces of folly.

Karin: Yeah, you could say that, indeed. (laughing)

Ulla: (laughter) That you know uh your weaknesses.

Karin: Uh-huh. Uh-huh.

Ulla: Yeah. (laughing)

Karin: Thank God! (in a lower voice)

Ingrid: Yeah, that's a good thing as long as you know them 'cause later (pause) later you do not dare trusting yourself there I I sometimes start to think "Ah well perhaps I don't really know this the way I think I do."

Ulla: No. No, exactly.

Initially Karin expresses confidence in her own experiential knowledge. Not only does she know her limitations better than anyone else; she is in control of her weaknesses to the extent that she can pass as healthy in spite of her internal struggles. Also, knowing that an active social life is rewarding once she overcomes her initial fears, Karin refuses to withdraw from it. Because of this experiential knowledge, she is at least to some extent in control of herself. 
However, there is a time perspective to her disease that complicates matters. Karin's short addition "Thank God," in a lower voice and a more serious tone, indicates that this kind of self-awareness cannot be taken for granted, at least not for very long. Ingrid explicitly addresses the fact that there is a time limit; later on one dares not trust oneself. Already she has started to doubt her own judgment and self-awareness, she confides.

Similar fears come up as Karin and Ulla discuss Karin's prospects of being accepted into a residential dementia care unit, according to her wishes. Ulla remarks that Karin is probably not confused enough.

Karin: It's like X, the podiatrist, said a few nights ago, "You know, none of us really believes you have dementia." "Yeah, I know" I said, "but I know I have."

Marie: Yeah.

Ulla: Yeah, exactly.

Marie: The thing is, you know, nobody-

Ulla: But as long as you're aware of that, they won't let you into dementia care.

Karin: Nobody cares about what I think. (ending utterance with laughter in her voice)

Ulla: No, exactly. Exactly. They'll wait until the day you stop thinking.

Karin: Yeah, that's what's so awful. Then I've caused lots of trouble, then then maybe I've half-way burned down the house.

Like in the example above, the group members recurrently talk about losing control, both in terms of what they have already lost and with reference to more advanced stages of dementia when they no longer expect to be able to make informed decisions. In this respect, experiential knowledge has limited authority. Similarly, group discussions frequently conclude about how little is known about the probable course of their diseases on an individual level, which causes great difficulties in planning for the future and making advance arrangements. Participants frequently express how insecure this makes them feel. As Clare (2002) puts it, people with progressive dementia diseases "need to find a balance between hope and despair." However, due to the progressive nature of the diseases, "the point of equilibrium could never be regarded as fixed, but would be continually shifting, requiring an ongoing process of adjustment" (p. 146).

Another important issue raised here is of course the scant attention being paid to a person's wish to be able to actively take part in the planning of her own future care; this will be addressed elsewhere. 


\section{Analytical Theme 2: \\ In-Between Trivialization and Dismissal- Facing Double Stigmatization}

The examples above, where people had a hard time believing that Karin has Alzheimer's, are but two of many. In group conversations, the participants often come back to how their children, spouses and others in their surroundings do not seem to grasp the extent of their difficulties. Dementia is after all invisible on the outside; a standing joke is that they should have their heads in plaster for everyone to see. Then perhaps people would be more sympathetic when they do "crazy stuff" such as grabbing somebody else's groceries by mistake at the counter - as Ulla describes, "when you stand there, wet through with perspiration, realizing 'Holy crap, these aren't my groceries!" The group members agree that people need to be informed of how dementia "comes creeping up on you." Even "the doctors" seem to lack this knowledge. Early signs are easily brushed away, resulting in negligence.

When group members inform others of their diagnoses, a common reaction is trivializing comments such as "Well, if you have dementia, then so have I." If that were the case, they conclude, that would imply that half of the town population would suffer from dementia. In contrast, the group members describe their problem as something completely different from ordinary forgetfulness.

Ulla: And even if I have papers to prove from a doctor, which I have, then it must be what I think. And if everyone (micropause) who says "If you're demented, then so am I" then there are then there aren't just twenty people in Littletown.

Karin: No no no.

Ingrid: No.

Ulla: Then you've got half of the town population.

Karin: Oh, yes. That's right. That's how it is. (laughing)

Marie: What is-

Ulla: 'Cause you know it's not just (micropause) like Karin tells us, it's the feeling when you experience

Mona: Yeah.

Ulla: that there's something wrong as well. That's different from before (micropause) when you forgot (micropause) ordinary forgetting.

Several: Uh-huh.

Ulla: That was one thing, you know. But now it feels completely different when you realize that you've done these crazy things. It's not like before, you know. 
Sinikka: No no.

Ingrid: The anguish, it's like-

Ulla: Yeah, exactly. So it's (micropause) well, you can't just shake it off

?: No.

Ulla: that I did something crazy, but it's still there afterwards, you know.

Ulla presents her experience as having general validity, frequently using expressions such as "you" and "you know." The general validity is confirmed by her listeners throughout her account by way of intensified feed-back ("No no no," "Oh, yes. That's right. That's how it is," etc.), and elaborative statements ("The anguish, it's like-"). The participants then continue to collectively describe the qualitative differences from "ordinary" forgetfulness. They mirror and elaborate on each other's utterances, thereby establishing a shared understanding (cf. Ohlsson, 2009). They conclude that their own more qualified problem means that they are no longer able to do what they used to do masterly. For instance, Karin, who used to cater professionally, now cannot decide whether or not to put salt in a dish. Also, as Sinikka remarks, the difficulties will increase over time. On another occasion, Ingrid describes not being able to recollect where she kept her winter coats - she searched in her bedroom and in her broom closet and all over the place before even thinking of her wardrobe. Also, there are other kinds of problems, such as being temporarily unable to find the door out of one's bedroom. With this experience, having one's diagnosis dismissed as ordinary forgetfulness is hurtful (cf. Beard, 2004; Sabat et al., 2004), although the group members do acknowledge that it is probably supposed to comfort them somehow.

On the other hand, group members may also find themselves being mistreated due to negative categorization.

Karin: You know, in the regular uh physical medical (micropause) treatment, like (pause) the rest of your body, then then then you're treated like "Yeah well, she's got Alzheimer's so it's (pause) it's nothing to worry about, it's just the way she is." (ending utterance with laughter in her voice)

Karl: It's categorizing people.

Karin: Yeah.

Karin describes having her agonies dismissed, perhaps even ridiculed, by a male nurse who advised her to have a throat lozenge as a tranquilizer. At that time, she was unable to assert herself. Afterwards, she did not report the incident, because, she asks her peers, "Whom would they believe?" Sinikka tells about the time her doctor, whom she consulted for a physical problem, asked her if she knew where she was - although she was there by herself, on time, and had properly paid for her visit at the counter. Many have had the experience that people 
in their surroundings do not know what to say to them. Karl suggests telling them "You know ... it's not contagious."

It seems that the members of Ingrid's group need to balance between two negative poles, so to speak - not unlike the sea monsters Scylla and Charybdis in-between which seafarers had to navigate in the Odyssey. On one hand, they risk having their problems trivialized, perhaps resulting in a lack of support or even disbelief. On the other hand, they risk being dismissed as mentally deranged due to negative categorization (cf. Karp, 1992). This may be referred to as double stigmatization (Ohlsson, 2009); it is a two-front battle. This is evident in the following example, where Karin tells about the night before. She was talking to her friends about her wants and needs in the face of the evolving disease.

Karin: And then they say "Yeah, but I can't understand that there's something wrong with you", they say. "You know, you take part in the conversation like the rest of us."

Ulla: Yeah, that's terrible.

Karin: Yeah.

Ulla: Damn it!

Karin: Yeah. (laughing) "You know, you can't be so-"

Ingrid: Yeah, you can't be so (inaudible), you should just sit there.

Ulla: (laughs)

(widespread laughter)

Karin: Yeah sure.

Ingrid: That's what I've started to do sometimes. (laughing)

?: (laughs)

Karin: And just dribble or something. Yeah well it's (pause) the thing is that that they don't know (micropause) how we (pause)

Ingrid: How one feels.

Karin: react and how we feel when we're alone and how we manage.

In this sequence, the group members joke about the stereotypical image of dementia they seem to find implied in Karin's friends' utterances. In order to fit into the image, Karin would have to just sit there, dribbling. Now that she does not, people have a hard time understanding that she actually has Alzheimer's disease. As a result, she expresses feeling somewhat alienated from her friends, as they - in spite of their best of intentions - do not understand her feelings or the difficulties that she has to deal with on a daily basis. When talking about the lived experience of dementia, Karin uses the pronoun "we": how we feel when 
we are alone and how we manage. This implies a collective identity. In contrast, Karin's friends outside the group are put in a different category: "they."

The self-help group is a free zone from stigmatization and stereotypical images. In conversations, the participants do not hide their difficulties from each other. When losing it, they ask for assistance or simply suggest that someone else tell a story for a while, and then resume their account as soon as their memory returns. At one time, Ingrid and Stieg entered the place roaring with laughter. Still laughing, Ingrid then explained that they were unable to figure out what button to push in the elevator. Because of that, they had been going up and down, up and down-"I lost count at sixteen times," Ingrid declared. Twice Sinikka was late for the group meeting due to forgetfulness. Upon arrival she suggested, with pretended seriousness, that she might have a memory problem. The others played along and suggested that she see a doctor about it. The second time this happened, Karin stated cheerfully: "If you do remember my visit last Friday, I would like to thank you for a very pleasant and enjoyable evening."

The group members often comment that even today dementia diseases are associated with shame. Some of the members have the deliberate strategy to be very open about their diagnoses in their everyday life, to challenge the stigmatization; others are somewhat more careful, to spare others the discomfort and to avoid marginalization. They all agree that people need to stop avoiding the subject - dementia is nothing to be ashamed of.

\section{Analytical Theme 3: Being Part of a Bigger Picture}

In making sense of their situation, the members of Ingrid's group paint a picture of being interrelated with others and with the surrounding society - being part of a bigger picture. According to their experiential knowledge, the difficulties they face in their everyday life are not just symptoms, but bound by close ties to a social context and to other people's actions. In their perspective, people with dementia are subjects interacting with other subjects-agents, yet dependent on others' performances. Sinikka says that the worst thing in her situation, having early-stage Alzheimer's, is that people do not understand that they should not rush her, because then her mind "goes a complete blank". This is, for instance, the case when she and her husband are going somewhere.

Sinikka: Then he takes the car keys and sits down in the car

Ulla: Yeah.

Marie: Yeah.

Sinikka: and says "Let's go!"

Ulla: Yeah.

Sinikka: And then I'm totally 
Ulla: Uh-huh.

Sinikka: confused.

?: Uh-huh. Uh-huh uh-huh.

Sinikka: I forget my wallet and I

Ulla: Yeah.

Sinikka: forget to lock the door.

Ingrid: Uh-huh. Lock the door at home, yeah.

Ulla: Yeah.

Sinikka: Yeah, all that stuff.

?: Uh-huh uh-huh uh-huh.

Ulla: It better be completely calm, see!

Sinikka: And I was thinking of, you know, the eldercare. Or uh dementia care, too, uh the staff. Who are in such hurry and everything.

Sinikka describes herself as being confused in this situation, however not as a mere symptom of her disease. Her confusion is rather the result of faltering interaction. Also, she is not the only one being confused in situations like this. At the end of her story, she mentions implications for dementia care and eldercare in general. The listeners provide intensive feed-back throughout the story, and also elaborate on it, indicating that Sinikka's experience applies to them as well. In stories like this, actors in the surroundings are described as agents with certain responsibilities. Still, the person with dementia remains an agent as well, possessing initiative and intentions as well as reactions. As a preface to this story, Sinikka explicitly describes her situation with her husband as not being able to "get it into his head" that he needs to be calm and very specific when he asks her to do something. The way she describes it, she is not merely reacting to his actions, but also actively trying to do something about it (albeit unsuccessfully).

In the end of the example above, Sinikka frames her and her husband's communicative problem as a more general problem, applicable to a variety of situations in the eldercare. This kind of framing is quite common in the conversations; stories of private troubles are used as starting points for general discussions of good policy, injustices in the health care system, political priorities, and so forth. Correspondingly, in discussing the news or community matters, the group members often relate to the situation of living with dementia. As citizens, they are interconnected with their community and society; this is implied in the discursive organization of their conversations. It is also explicitly expressed, over and over again, in the data - in terms of wanting to be able to actively take part in decision-making while one still can; to take measures, as responsible 
citizens, to prevent mishaps due to the evolving disease; and to make an imprint on how people talk about dementia.

\section{DISCUSSION}

The conversations of Ingrid's group challenge stereotypical images of dementia in our society in several respects. In a social context where people with these kinds of cognitive impairment are rarely included in the discourse concerning their own diseases, these self-help group members discuss their condition with great self-awareness, esprit, and candor. With little interference from the professionals, they collaboratively build up their own body of experiential and mutually shared knowledge, while simultaneously being questioned by people around them in different ways. Although expected by their surrounding society to yield to the passive patient role, they persist in actively developing a perspective of their own in the face of evolving dementia. In line with theories of self-help, this could be understood as a meaning perspective in its making. But what kind of meaning is constructed? To what extent is there a "liberating" meaning perspective?

In the conversations a complex picture emerges. For instance, experiential knowledge is continuously co-constructed and highly valued in the group, however always facing the imminent threat of being overthrown by disease progression in what may be described as a battle with time. On one hand, the participants jointly establish a common image of what it is like to live with dementia. In sharing their individual experiences and making comparisons, they expand their knowledge base. They mirror each other's experiences and fill in each other's sentences, thereby constructing a collective identity. Intensified feed-back and evaluative statements confirm a shared understanding of what is being told and what it is all about. Constructions like "you" (Swedish: "man"), in a general sense, and "you know" (the Swedish adverbial construction "ju") give general validity to statements. Personal stories function as starting points for more general discussions, sometimes in the shape of recurrent prototypical examples used for the construction of arguments. Altogether, this creates an accumulated body of experiential knowledge that is used for coping and managing everyday challenges as well as for the purposes of identity construction and meaning-making. It gives the group members a certain amount of confidence in relation to negative expectations and stereotypical images emanating from the surrounding society. This is indeed liberating.

Yet, the shadow of the unknown future, to which their experiential knowledge will not apply, is always imminent. Sometimes it is referred to explicitly, in terms of "the day you stop thinking" or "later" when you "do not dare trusting yourself." At other times there are merely vague hints. Time references may be mentioned in passing, as in what one is capable of "now" (in contrast to later) or what one has "recently" noticed as problematic (indicating deterioration). 
Decisions are mentioned that mark the pathway to a more confined existence. I believe it is safe to say that this has consequences for the development of the group's meaning perspective. Most likely, no meaning perspective will ever be sufficient for "resolving," once and for all, a problem that so ruthlessly expands and takes new shapes, and with such an unpredictable course on the individual level. In their struggling for meaning, the members of Ingrid's group constantly face new challenges. They have to live with the uncertainty of not knowing what will be the next blow, or when. Theories of group development, thus, do not seem applicable to self-help groups for people with dementia-at least not at this level of medical advancement. No matter how devoted to learning and developing, the group will never reach a stage of complete faith in its experiential authority. In this sense, the meaning perspective and its possibilities for liberation are limited.

To complicate matters further, the participants need to constantly balance the risks of having their difficulties neglected or trivialized, on one hand, and of being dismissed as mentally deranged on the other hand. To avoid stigmatization, they have to fight a two-front battle. It is evident from the data that the group members devote a lot of energy to co-constructing the image of their problem as something qualitatively different from, for instance, ordinary forgetfulness. The distinction is outlined by means of concrete examples clearly illustrating the difference, drawing on the group's experiential knowledge. The status of having a disease is essential to the group identity as a means to avoid the shame and blame that their difficulties may otherwise pose upon them. At the same time, the participants embrace the notion of dementia as something that "creeps up on you" in a less obvious way. This may seem paradoxical, as it may actually contribute to blurring the distinction between dementia and normal forgetfulness. However, once again, experiential knowledge is the key. The accumulated experiences of the group have merged into a knowledge base that gives its members the authority to make this distinction. Put simply, "it takes one to know one." This is put forward as important information for the purpose of helping others, as early signs of dementia are still far too often neglected or misinterpreted. Claiming authority in this area as experientialists, group members have found the confidence to educate doctors, nurses, decision-makers, as well as the public.

As for the other end of the spectrum, stigmatization due to negative categorization, the testimonies put forward paint a darker picture. In talking about these matters, participants are more likely than otherwise to yield to helplessness and passive resignation. Although they find the matter worth a fight, the chance of winning it is often depicted as scant. The group members do work up a fighting spirit from time to time, but this spirit is highly dependent on the active efforts of a few participants and thus very fragile.

In contrast, the self-help group seems to provide a haven of refuge. The group members have jointly created a framework of sincerity, openness and 
genuine concern for each other. Communicative difficulties that might otherwise be disruptive are no big deal in these conversations. Forgetfulness is often a source of recognition and shared amusement. I also wish to take the opportunity to clarify that during the one and a half years that I took part in these group meetings, there was never any need for professional intervention to handle fluctuations in affect or behavior, let alone agitation. In the entire corpus of data, there is not one single instance of dissension. Although strong emotions were allowed to be expressed, the situation was never out of control. Except for one unfortunate incident of tripping over a walking-frame, nothing "unexpected" ever happened in this activity.

The safe haven of the group meetings is however not enough. The perhaps most liberating aspect of the group's meaning perspective is its air of interrelatedness with other people, the community, and society. The meaning perspective that takes shape in the group conversations is not restricted to personal matters. Rather, the experienced difficulties are discussed within the framework of their interactional and social context, in line with the citizenship perspective outlined by Bartlett and O'Connor (2007). Personal, interpersonal, and political matters are discursively intertwined in the topical pathways throughout the large body of empirical data. Factors in the interactional environment - in close relationships as well as interaction with the health care and welfare systems - are recognized as having great importance.

The vulnerability to marginalization, evident in the participants' experiences of negative categorization and mistreatment, is consistent with this perspective. Power dynamics are, after all, inherent in any image of interdependence. It is however essential for the meaning perspective to move beyond the victim position to an actor position. In the self-help group conversations, participants do construct themselves as prospective agents, wanting to actively take part in decision-making and planning for their future care. In the discourse they stand out as both able and willing to act as responsible citizens as long as they are still capable of informed decision-making. However, it is a construction in need of scaffolding, so to speak, as there are also lines of argument leading to a construct of helplessness and resignation.

Interestingly, this allows for a shift in focus from strictly medical models to not only psychosocial ones, but also to a citizenship perspective. After all, the self-help group does not operate in a vacuum. Many forces are at work when meaning perspectives develop. The discursive constructs of meaning within the self-help group are interrelated with values, beliefs, interests and practices of society. This is clear not only from a theoretical point of view; it is evident from the empirical data. As we have seen, the group's meaning perspective cannot be isolated from the broader socio-political context from which it emanates. In the case of Ingrid's group, it is evident that both social and structural barriers make a deep mark on the meaning-making process, adding to the despair brought on by the disease itself. 
In listening to the collective stories told by people with dementia in selfhelp groups, we may be able to work together to avoid at least some of the topical pathways that lead to feelings of helplessness and despair. For this to happen, I believe it is necessary not only to change the way we think of dementia, but also to make some vital changes in care practice and in the welfare system. We need to make it easier for people with dementia to act as responsible citizens and exercise the power to which they are entitled in terms of civil rights.

\section{Implications for Practice: Promoting Citizenship}

First of all, it is essential that people with dementia be provided opportunities and venues for sharing and mutual support. The findings from this explorative study not only support earlier findings that people with dementia may benefit from the feelings of belonging, mutual concerns, and emotional support that may take place in the context of the self-help group. They may also-at least in their early stages - be able to develop liberating meaning perspectives of their own (albeit with some limitations) independent of professional authority and control. Professionally led and more socially oriented occupational programs do not even begin to address the needs within this group of citizens, as displayed in Ingrid's group, to be able to take charge of their situation. People with dementia may be less inclined to get activities started and keep them going (as these functions are often hampered by the disease even at an early stage); for such purposes professional guidance may be required. Nevertheless, the agency, motivation and remaining competence of persons with dementia should not be underestimated. Ingrid's group provides fine examples of citizens assuming responsibility for their own learning and development as well as for group processes and dynamics.

People like Ingrid and her friends should be encouraged and enabled to join forces and, so to speak, put their heads together. As peers running their own activity, the members of Ingrid's group form a sense of togetherness which enables an exchange of learning to take place (cf. Avis et al., 2008). I strongly believe that this kind of mutual responsibility, for the development of the group and its knowledge base, empowers people to take on citizenship. As part of a group exchanging mutual aid and support, they are able to accomplish much more than they would individually. That is, in terms of self-help - coping, coming to terms with their situation, and finding new strategies when applicable - but also in putting into words what would allow them to make the best of their situation. This, in turn, could be the germ of social change.

The concept of mutuality is key here, which poses complex challenges for professionals administrating the self-help group activity. For mutuality to develop, they need to remain in the background, like Marie, and encourage and 
support the experientialists to actively form their own agenda based on their mutual interests. Professionals need to provide the space and services needed, perhaps push a little, yet refrain from pointing out any directions. This may be an extremely hard role for professionals to take on; acknowledging that their professional knowledge and models of thinking are not authority, they are no longer on solid ground. On the other hand, there is much to be gained from exploring new territory.

Many lessons can be learned from experientialist knowledge and perspectives when it comes to dealing with conditions as deeply feared as dementia. The challenges of double stigmatization evident from Ingrid's group demonstrate clearly the need for increased public awareness of the subtle nuances of living with and through dementia. Care practitioners, decision-makers, relatives, friends, and neighbors need to learn to recognize the difficulties that people with dementia experience in their everyday life; yet refrain from any devaluing negative categorization that may restrict the agency of this group of people. Professional and voluntary organizations could benefit greatly from acknowledging experiential authority and cooperating with self-help groups to make improvements within this area.

This brings me to my next point. We need to recognize the political and social significance of the accumulated experiential knowledge and perspectives emanating from dementia self-help groups. Experientialist voices should be included in the public discourse to inform decision-making in health and welfare institutions with regard to their civil rights. Perhaps it would also be possible to find ways for people with early-stage dementia to be actively involved in the planning of their future care, instead of being forced to passively wait for others to make decisions for them at a stage when they are no longer able to take part in the process. Finding ways to allow experientialist perspectives to have a real imprint on decision-making and practices of health and welfare is a major challenge. Only then will we be able to fully appraise the opportunities for social change embedded within self-help group activity as regards this group of citizens.

\section{REFERENCES}

Adamsen, L. (2002). "From victim to agent": The clinical and social significance of self-help group participation for people with life-threatening diseases. Scandinavian Journal of Caring Sciences, 16, 224-231.

Avis, M., Elkan, R., Patel, S., Walker, B. A., Ankti, N., \& Bell, C. (2008). Ethnicity and participation in cancer self-help groups. Psycho-Oncology, 17, 940-947.

Baldwin, C. (2008). Narrative(,) citizenship and dementia: The personal and the political. Journal of Aging Studies, 22, 222-228. 
Ballenger, J. F. (2006). The biomedical deconstruction of senility and the persistent stigmatization of old age in the United States. In A. Leibing \& L. Cohen (Eds.), Thinking about dementia: Culture, loss, and the anthropology of senility (pp. 106-120). New Brunswick, NJ and London: Rutgers University Press.

Bartlett, R., \& O'Connor, D. (2007). From personhood to citizenship: Broadening the lens for dementia practice and research. Journal of Aging Studies, 21, 107-118.

Beard, R. L. (2004). Advocating voice: Organizational, historical and social milieux of the Alzheimer's disease movement. Sociology of Health \& Illness, 26, 797-819.

Beard, R. L., \& Fox, P. J. (2008). Resisting social disenfranchisement: Negotiating collective identities and everyday life with memory loss. Social Science \& Medicine, $66,1509-1520$.

Beard, R. L., Knauss, J., \& Moyer, D. (2009). Managing disability and enjoying life: How we reframe dementia through personal narratives. Journal of Aging Studies, 23, 227-235.

Borkman, T. (1976). Experiential knowledge: A new concept for the analysis of self-help groups. The Social Service Review, 50, 445-456.

Borkman, T. (1999). Understanding self-help/mutual aid: Experiential learning in the commons. New Brunswick, NJ and London: Rutgers University Press.

Borkman, T. (2008). Self-help groups as participatory action. In R. A. Cnaan \& C. Milofski (Eds.), Handbook of community movements and local organizations (pp. 211-226). New York: Springer.

Bülow, P. H. (2004). Sharing experiences of contested illness by storytelling. Discourse \& Society, 15, 33-53.

Carlsen, B. (2003). Professional support of self-help groups: A support group project for Chronic Fatigue Syndrome patients. British Journal of Guidance \& Counselling, 31, 289-303.

Clare, L. (2002). We'll fight it as long as we can: Coping with the onset of Alzheimer's disease. Aging \& Mental Health, 6(2), 139-148.

Clare, L., Rowlands, J. M., \& Quin, R. (2008). The impact of developing a shared social identity in early-stage dementia. Dementia: The International Journal of Social Research and Practice, 7, 9-30.

Corner, L., \& Bond, J. (2004). Being at risk of dementia: Fears and anxieties of older adults. Journal of Aging Studies, 18, 143-155.

Goldsilver, P. M., \& Gruneir, M. R. B. (2001). Early stage dementia group: An innovative model of support for individuals in the early stages of dementia. American Journal of Alzheimer's Disease and Other Dementias, 16, 109-114.

Jacobs, M. K., \& Goodman, G. (1989). Psychology and self-help groups: Predictions on a partnership. American Psychologist, 44, 536-545.

Karp, D. A. (1992). Illness ambiguity and the search for meaning: A case study of a self-help group for affective disorders. Journal of Contemporary Ethnography, 21, 139-70.

Kitwood, T. (1988). The technical, the personal and the framing of dementia. Social Behaviour, 3, 161-179.

LaBarge, E., \& Trtanj, F. (1995). A support group for people in the early stages of dementia of the Alzheimer type. Journal of Applied Gerontology, 14, 289-301. 
Linell, P., Wibeck, V., Adelswärd, V., \& Bakshi, A.-S. (2001). Arguing in conversation as a case of distributed cognition: Discussing biotechnology in focus groups. In E. T. Németh (Ed.), Cognition in language use: Selected papers from the 7th International Pragmatics Conference, Vol. 1 (pp. 243-255). Antwerp: International Pragmatics Association.

Mason, E., Clare, L., \& Pistrang, N. (2005). Processes and experiences of mutual support in professionally-led support groups for people with early-stage dementia. Dementia: The International Journal of Social Research and Practice, 4, 87-112.

Milofski, C. (2008). Small towns and mass society. In R. A. Cnaan \& C. Milofski (Eds.), Handbook of community movements and local organizations (pp. 60-73). New York: Springer.

Mountain, G. (2006). Self-management for people with early dementia: An exploration of concepts and supporting evidence. Dementia: The International Journal of Social Research and Practice, 5, 429-446.

National Swedish Board of Health and Welfare. (2010). Nationella riktlinjer för vård och omsorg vid demenssjukdom [National Guidelines for Dementia Care]. Retrieved from the NSBHW website: http://www.socialstyrelse.se/publikationer2010/2010-5-1

Ohlsson, R. (2009). Representationer av psykisk ohälsa: Egna erfarenheter och dialogiskt meningsskapande $\mathrm{i}$ fokusgruppsamtal [Representations of mental illness. Illness experience and the dialogical construction of meaning in focus group discourse]. $\mathrm{PhD}$ dissertation, Department of Education, Stockholm University, Stockholm.

Pearce, A., Clare, L., \& Pistrang, N. (2002). Managing sense of self: Coping in the early stages of Alzheimer's disease. Dementia: The International Journal of Social Research and Practice, 1, 173-192.

Sabat, S. R., Napolitano, L., \& Fath, H. (2004). Barriers to the construction of a valued social identity: A case study of Alzheimer's disease. American Journal of Alzheimer's Disease and Other Dementias, 19, 177-185.

Schubert, M. A., \& Borkman, T. J. (1991). An organizational typology for self-help groups. American Journal of Community Psychology, 19, 769-787.

Sterin, G. J. (2002). Essay on a word: A lived experience of Alzheimer's disease. Dementia: The International Journal of Social Research and Practice, 1, 7-10.

Taghizadeh Larsson, A., Jeppsson Grassman, E., \& Whitaker, A. (2010). Brukarmedverkan-visioner och verkligheter. En utvärdering av 32 projekt som på olika sätt rör äldre [User involvement-visions and realities. An evaluation of 32 projects involving the elderly in different ways]. National Institute for the Study of Ageing and Later Life (NISAL), Linköping University.

Toro, P. A., Reischl, T. M., Zimmerman, M. A., Rappaport, J., Seidman, E., Luke, D. A., et al. (1988). Professionals in mutual help groups: Impact on social climate and members' behavior. Journal of Consulting and Clinical Psychology, 56, 631-632.

Vernooij-Dassen, M. J. F. J., Moniz-Cook, E. D., Woods, R. T., De Lepeleire, J., Leuschner, A., Zanetti, O., et al. (2005). Factors affecting timely recognition and diagnosis of dementia across Europe: From awareness to stigma. International Journal of Geriatric Psychiatry, 20, 377-386.

Yale, R. (1999). Support groups and other services for individuals with early-stage Alzheimer's disease. Generations: Journal of the American Society on Aging, 23(3), 57-61. 
Yale, R., \& Snyder, L. (2002). The experience of support groups for persons with early-stage Alzheimer's disease and their families. In P. B. Harris (Ed.), The person with Alzheimer's disease: Pathways to understanding the experience (pp. 228-245). Baltimore and London: The Johns Hopkins University Press.

Direct reprint requests to:

Linda Örulv

Center for Dementia Research (CEDER), and

Department of Medical and Health Sciences

Division of Health and Society

Linköping University

SE-581 83 Linköping

Sweden

e-mail: linda.orulv@liu.se 